\title{
A HISTÓRIA NA E PELA SALA DE AULA: A RELAÇÃO ENTRE PROFESSORES DO 'ENSINO BÁSICO’ E DO 'ENSINO SUPERIOR' A PARTIR DO PDE-PR
}

\author{
LA HISTORIA EN Y POR LA SALA DE AULA: LA RELACIÓN ENTRE \\ PROFESORES DE 'LA EDUCACIÓN BÁSICA'Y DE LA 'EDUCACIÓN \\ SUPERIOR'A PARTIR DEL PDE-PR
}

\begin{abstract}
THE HISTORY IN AND FOR THE CLASSROOM: THE RELATIONSHIP BETWEEN TEACHERS OF 'K-12 EDUCATION' AND PROFESSORS OF 'HIGHER EDUCATION' HAVING PDE-PR AS STARTING POINT
\end{abstract}

\author{
Jorge PAGLIARINI JUNIOR ${ }^{1}$
}

RESUMO: Nas duas últimas décadas, o entendimento das prerrogativas decorrentes da relação entre ensino e pesquisa tem desafiado profissionais de diferentes áreas do saber, e os resultados dessa interação passaram a integrar professores do ensino básico e do superior em torno do desenvolvimento de projetos de ensino. $\mathrm{O}$ artigo apresenta atividades realizadas na Unespar, Campo Mourão - PR, no e pelo Programa de Desenvolvimento da Educacional (PDE) do Paraná, curso de formação continuada dos professores da rede de ensino básico do Estado, e, com isso, direciona um debate epistemológico pautado na relação de trocas de experiências entre os professores envolvidos, professores universitários orientadores e os professores da rede básica, ora na condição de alunos. Acredita-se que esse enfoque possa implicar melhorias nas metodologias aplicadas, no embasamento teórico das atividades docentes desenvolvidas e na concepção desses profissionais a respeito dos significados do conhecimento histórico a ser vivenciado no sistema público estadual de ensino.

PALAVRAS CHAVES: Formação continuada. Conhecimento histórico. Ensino e pesquisa.

RESUMEN: En las últimas dos décadas, la comprensión de las prerrogativas derivadas de la relación entre la enseñanza y la investigación ha desafiado a profesionales de diferentes áreas de conocimiento y los resultados de esta interacción se han unido a los maestros de educación básica y superior en torno del desarrollo de proyectos de enseñanza. Este estudio presenta actividades realizadas en la Universidade Estadual do Paraná - Unespar, Campo Mourão - PR, en (y por) el Programa de Desarrollo de la Educación (PDE) del Paraná, curso de educación continua para los maestros del sistema de educación pública básica del Estado y, por lo tanto, dirige un debate epistemológico pautado en la relación con el intercambio de experiencias entre los profesores implicados - profesores universitarios y maestros de la educación básica ahora como estudiantes. Se cree que este enfoque puede traer mejoras en las metodologías aplicadas, en la base teórica de las actividades de

1 Prof. Adjunto do curso de História da Unespar - Campus de Campo Mourão-PR. E-mail: palhajr@yahoo.com.br

RIAEE - Revista Ibero-Americana de Estudos em Educação, v. 12, n. 2, p.884-899, 2017.

E-ISSN: 1982-5587 
enseñanza desarrolladas y en la concepción de estos profesionales acerca de los significados del conocimiento histórico que se experimentó en el sistema de escuelas públicas del Estado.

PALABRAS-CLAVE: Educación continua. Conocimiento histórico. La enseñanza y la investigación.

ABSTRACT: In the last two decades, the understanding of the prerogatives associated with the relationship between teaching and research has challenged professionals from different areas of knowledge, and the results of this interaction have begun to include teachers from both $\mathrm{K}-12$ and higher education around the development of educational teaching projects. The article presents activities accomplished at Unespar, Campo Mourão - PR, in/for the 'Programa de Desenvolvimento da Educação' - PDE (Program of Educational Development) from Paraná - a continuing education course for teachers from Paraná K-12 educational system. Hence, the study directs an epistemological debate based on the relations of exchange of experiences with the teachers encompassed, namely, advising professors and, in the role of students, various $K-12$ teachers. One believes that this approach may trigger improvements to the applied methodologies, to the theoretical basis of accomplished teaching activities and to the conception of these professionals regarding the meanings of historical knowledge to be experienced at the Paraná state public school educational system.

KEYWORDS: Continuing education. Historical knowledge. Teaching and research.

\section{Introdução:}

"As coisas eram difíceis, hoje é bem mais fácil, mas em termo de ser feliz, era mais feliz na ilha" ${ }^{2}$. A afirmativa serve de provocação, e com ela iniciamos este artigo estruturado na problematização de experiências de orientação. A frase resulta de análise e transcrição de fragmento de uma entrevista preocupada com os viveres de moradores de uma cidade do Estado do Paraná, realizada por um aluno do $9^{\circ}$ ano do ensino básico da rede pública, sob a supervisão da professora que aplicava, na oportunidade, uma atividade do Programa de Desenvolvimento da Educação do Paraná (PDE). Esse projeto, por sua vez, faz parte de um total de 48 projetos da área de História desenvolvidos na Unespar, campus de Campo Mourão-PR, nos últimos 6 anos, sendo, desse total, 11 deles por nós orientados entre os anos de 2012 a 2014, e com o seu exemplo, chamávamos a atenção aos desafios presentes na utilização de narrativas orais

\footnotetext{
${ }^{2}$ Baseado nas memórias de um morador de Porto Camargo sob a orientação da professora responsável pelo PDE. Na sua aplicação se buscou problematizar as memórias de ribeirinhos que vivenciaram o processo de construção do Parque de Ilha Grande naquela região, tendo ainda a preocupação da produção de material didático pelos e para os alunos envolvidos no projeto.
} 
em sala de aula a partir do recorte da História Local. Quanto à metodologia aplicada nessa atividade, podemos destacar que os alunos foram orientados a exercitar sua imaginação histórica ao produzirem entrevistas semiestruturadas. Cabe enfatizar que se trata de imaginação, pois eles deveriam interpretar o significado, nesse caso, de um morador do município que viveu um processo migratório, da ilha para a cidade, após a criação de um Parque Ambiental naquele local; o morador se lembrara, na ocasião, de um passado no qual a vida que levava era difícil, porém feliz.

A metodologia valorizaria a inserção do aluno no estudo histórico, no trato com fontes históricas e na produção de narrativas. Ocorre, no entanto, que o exemplo nos desafia ainda a valorizar o papel do professor nesse processo de produção de conhecimento e, por consequência, o papel dos orientadores do Programa diante da relação entre ensino básico e ensino superior, sobretudo no que tange à abordagem epistemológica que a estruturou.

A atividade citada constitui-se de filtros representados pela interpretação do aluno a respeito de memórias de vida de um morador da sua localidade; pelo olhar e orientação da atividade realizada pela professora da turma e, ainda, pela sua utilização enquanto um dos exemplos a serem discutidos em forma de artigo e que apresentaria o processo vivenciado por ela na sua formação no PDE, numa escrita orientada. Voltando à atividade poderíamos pensar: a narrativa histórica da qual resultou é de fato do aluno, ou de sua professora? Ou do orientador do PDE?

Essas questões direcionam a uma abordagem teórica e metodológica e, consequentemente, a uma problemática epistemológica. Podemos aqui adiantar, trata-se do construtivismo.

A interpretação da atividade considera implicações epistemológicas que envolvem alguns filtros presentes no seu processo de construção, os quais no direcionam para a problemática central do nosso artigo, quer seja problematizar exemplos da produção do conhecimento diante das intermediações do ensino básico e do superior. Para tanto, o debate seguirá dividido em três abordagens. Numa primeira, apresentaremos o PDE e defenderemos as contribuições do Programa no sentido de possibilitar a aproximação entre ensino e pesquisa, além da valorização da relação entre ensino e historiografia e da narrativa histórica.

No segundo momento, o debate aproxima-se da análise epistemológica apresentada por Ciro Flamarion, no início da obra, e por Vainfas no encerramento da mesma, presentes no parecer sobre as pesquisas do campo da História nas duas últimas 
décadas (CARDOSO; VAINFAS, 1997) e avalia, então, como as pesquisas contemporâneas e suas respectivas metodologias colocam em xeque certezas quanto à desvalorização do reconstrutivismo, tendo aqui a particularidade de se pensar tal problemática no e pelo ensino. Destacaremos como os professores do PDE, via de regra, confiam na sua capacidade de pesquisa, justamente por "conhecerem" a "história local", os fatos e os eventos que a constituem, e, a partir desta experiência profissional e social, buscam, justamente no conhecimento das fontes e na proximidade com o aluno e com a dinâmica da localidade estudada, um posicionar-se diante das cobranças do programa PDE.

No último momento do texto apresentaremos alguns resultados do projeto do qual faz parte o fragmento da entrevistada citada acima, avaliando, com isso, as especificidades da relação de formação e de desenvolvimento das atividades, com destaque para aquilo que os professores buscaram na formação PDE e principalmente, para as mediações entre orientadores e orientados, algo que acreditamos vai além da constatação da dicotomia que, a priori, colocaria em campos opostos os professores alunos, detentores do saber local, e os professores orientadores, conhecedores de teorias.

\section{O PDE - o reencontro com o ensino básico e o reencontro com a pós-graduação}

No ano de 2009, a Unespar, Campus de Campo Mourão, então Faculdades de Ciências e Letras de Campo Mourão (Fecilcam), aderiu ao PDE e, com isso, possibilitou que parte dos professores vinculados aos núcleos regionais de educação da Comunidade dos Municípios da Região de Campo Mourão (Comcam) passasse a frequentar ali o programa de maneira integral ${ }^{3}$. Na sua formatação, o PDE implica, diretamente, a efetivação da relação entre pesquisa e ensino e tem ênfase na produção de material para o ensino. Os professores-alunos do Programa passam um ano afastados integralmente das atividades de sala de aula e produzem, nesse período, um material didático voltado aos seus alunos dos colégios ou aos seus pares (a produção de produtos, como de softwares, também é possível). No segundo ano aplicam esse

${ }^{3}$ O PDE incorporou parte significativa dos esforços das licenciaturas de Letras, Matemática, Geografia e, posteriormente, do recém-criado Curso de História daquela instituição. As expectativas eram de ordem institucional, pois envolviam instituições como a própria universidade, além dos núcleos regionais de educação e os colégios, e de ordem formativa/cognitiva, ao atentar para as prerrogativas e para os anseios dos orientados e de orientadores em torno do potencial agregador do PDE para o ensino. 
material no $1^{\circ}$ semestre, cabendo ao período do $2^{\circ}$ semestre a produção de artigo final sobre o processo. Nese segundo ano, a volta à sala de aula ocorre numa proporção de 75\%. No caso das nossas 11 orientações concluídas, optamos pela modalidade de caderno pedagógico, no qual a construção de algumas unidades didáticas deveria apresentar um material formado por atividades destinadas diretamente aos alunos, além das devidas orientações para os professores.

Os resultados dos projetos desenvolvidos e aqui problematizados na sua relação entre professores das instituições envolvidas e nas demandas da formação podem ser apresentados pela analogia representada por Nóvoa (1999) ao situar o ensino na contemporaneidade, abordagem na qual utiliza da metáfora dos vértices do triângulo ${ }^{4}$.

Para o autor, historicamente, o status de valorização dos vértices integrantes do sistema educacional partiria da valorização certa do vértice representado pelo professor, lugar adjetivado pelo autor pelo termo "experiência", e esse vértice se aproximaria ora do vértice representante do saber pedagógico, isso em momentos de renovação do campo, e com isso distanciando-se do vértice do saber das disciplinas, o qual seria então o morto, ora aproximando-se do saber das disciplinas e, por conseguinte, distanciandose do saber pedagógico, posicionamento típico de momentos conservadores. Ocorre que agora, segundo o autor, são os saberes pedagógicos e o das disciplinas (conteúdos) que se aproximam e o vértice do professor - o vértice da experiência - é que acaba afastado da produção do saber, assumindo pela primeira vez, sistematicamente, o lugar do morto.

Se não se quer assumir aqui o esquema de vértices nem se quer aplicá-lo à realidade do nosso sistema educacional para determinar onde estaria o morto - se nos professores, se no saber pedagógico ou se nas disciplinas -, pode-se, ao menos, utilizálo a título de apresentação da realidade vivenciada pelos professores envolvidos no PDE e, assim, sem que chegássemos a apontar aqui para o morto, pensar a abrangência e a heterogeneidade do vértice da experiência. A questão avalia a possibilidade de

\footnotetext{
${ }^{4}$ Análise resultante da apresentação de outros dois triângulos, o do triângulo pedagógico, cujos vértices são ocupados pelo professor, pelo saber e pelos alunos; e do triângulo político, por sua vez, composto pelo professor, pelo Estado e pelos pais. Ao se posicionar diante das inovações educacionais típicas, segundo ele, dos anos de 1990 - isso em fins dessa mesma década -, Nóvoa retoma a teoria dos vértices do triângulo, ou seja, de três lugares assumidos pelo sistema educacional para apresentar um "morto" resultante do distanciamento de dois vértices deste triângulo do conhecimento de um terceiro vértice, o morto, cabendo assim a intensificação dos usos e a respectiva valorização desses dois vértices, e a desvalorização do terceiro, o qual, mesmo excluído das atenções, segue formando a tríade do circuito educativo, tal qual um morto no jogo de bridge diante das mãos (cartas) dos dois jogadores, que a ele recorrem diante de suas estratégias de jogo.
} 
professores universitários/orientadores e professores-alunos/orientandos se situarem num mesmo vértice do triângulo - o da experiência. Também problematiza até que ponto a interação com o saber pedagógico e com os conteúdos se daria numa mesma intensidade entre eles. Antes desse debate, cabe destacar exemplos de como o PDE propicia a valorização da relação entre pesquisa e ensino, objetivo da intervenção nos colégios 5 .

Desde a construção do projeto, passando pela dinâmica concebida e tutoreada em rede (on-line) para outros professores interessados, mas ainda não vinculados ao Programa, e chegando à produção e à posterior aplicação de material didático e a sua disseminação pelo Portal do Educador da SEED/PR, todos os passos cobram dos profissionais envolvidos a pesquisa histórica e a inserção no debate historiográfico.

O PDE tem com principal objetivo a construção de um conhecimento histórico compromissado com as demandas do ensino. Nossa atuação no programa aproximou-se daquilo que Cerri (2009) ${ }^{6}$ destacou ao afirmar ser o ensino de História um problema da própria História. Aqui poderíamos retomar o desafio de se pensar as correntes no decorrer das orientações do PDE e isso nos remeteria ao esforço de reconhecimento e de reflexão do fenômeno historiográfico e seus usos sociais. Ainda próximos ao autor considerarmos que, além das práticas diretamente ligadas ao colégio, outros diferentes caminhos indicam o processo de construção de consciência histórica, e esses, por sua vez, interferem no ensino de História (Idem, ibidem, p. 150). Pode-se então avaliar como os usos políticos e cognitivos da História interferem no estudo da historiografia da História regional. Isso repercute nos casos por nós orientados, na necessidade de se considerar toda uma produção oficializada das histórias dos municípios, reproduzida em sites de órgãos públicos municipais e outros oficiais similares, e em bibliografias de “diletantes”. Em síntese, essas análises implicaram uma perspectiva de produção dialogal do conhecimento.

\footnotetext{
${ }^{5}$ Além da produção de material didático, o PDE possibilita, em outras linhas, a escolha pela produção de cadernos temáticos, estruturados em um debate mais teórico-metodológico destinado à formação dos profissionais ou mesmo de softwares educacionais e outros materiais didáticos e, por isso, voltados à aplicação com equipe docente e não diretamente com os alunos. Como os trabalhos aqui apresentados se destinaram a esta primeira modalidade, seguiremos tendo por base os resultados advindos da pesquisa e da materialização dela a partir do caderno pedagógico.

${ }^{6} \mathrm{O}$ autor dividiu as concepções do ensino em dois grupos: (i) um representante das perspectivas que não valorizam a relação intrínseca entre ensino e historiografia; (ii) outro, que concebe o ensino e a pesquisa como elos de um processo de produção do conhecimento histórico, grupo dividido entre as correntes tradicional, crítica e ontogenética, estando esta última ressaltada a partir das contribuições do autor.
} 
Outra contribuição do Programa encontra-se na renovação do campo da História no que se refere a um paradigma regional. Atenta-se aí aos processos desiguais da produção resultante da pesquisa histórica orientada pelo Programa e necessita lidar com identidades enquanto sinônimas de construções históricas permeadas por discursos, por ressignificações, por disputas e por silenciamentos. O resultado dos projetos de fato significou a construção de material didático voltado à História regional, trabalho permeado por cobranças advindas desde as indicações das linhas de pesquisa delimitadas pelos núcleos regionais de educação. Tal posicionamento repercutiu positivamente nos projetos orientados, e a esse propósito nos aproximamos de Martins (2010) e com ele percebemos que o estudo do espaço, mais do que uma delimitação espacial, nos leva a atentar para redes de relação social e para jogos de escalas identificados em meio ao estudo de fenômenos sociais, reconhecendo-se, com isso, as limitações de um modelo de História regional que apenas reproduzisse o debate nacional, numa perspectiva tradicional, sem questionar a estrutura e a própria construção e análise histórica dos sujeitos inseridos numa escala espacial menor ${ }^{7}$.

Além da ênfase à História regional, as aulas destinadas à intervenção tiveram por base as potencialidades da narrativa histórica. Uma das demandas das orientações se situou justamente na fronteira demarcada por Mattos (2007) entre um modelo de narrativa histórica típica da primeira metade do século passado, a do Estado-Nação, combatida a partir da introdução da corrente representada pelo autor por Furet com a "História Problema", e a forma de narrativa histórica que valorize a contribuição de uma aula narrada-expositiva, uma aula-texto, segundo o mesmo autor ${ }^{8}$. Nessa confluência entre aula e texto, sem desconsiderar a importância da história-problema, situamos nosso posicionamento sobre os usos da narrativa histórica no PDE.

\footnotetext{
${ }^{7}$ Esse esforço dialogou tanto com os limites da historiografia dita "oficial", há pouco lembradas, quanto com leituras carregadas de certo vitimismo histórico e, em outros casos, com materiais didáticos e fontes voltadas mais à construção da crítica pelo aluno e menos ao conteúdo histórico. A nossa abordagem regional esteve atenta àquilo que Escorsi (2013) denominou "riscos epistemológicos" da temática regional. $\mathrm{O}$ autor parte do fato de que o currículo e o manual se tornam, no atual contexto de redemocratização, um território a ser conquistado e assim argumenta, a partir dos resultados por ele alcançados com a pesquisa de currículos e manuais didáticos, que a valorização de um discurso de pequenas identidades diante da crítica da lógica educacional do Estado-Nação. Nisso conclui apresentando aquilo que denomina como "biografia dos guetos", resultante da "celebração das identidades" e da respectiva "morte da política", numa relação de ganho democrático acompanhado de uma produção "laudatória" resultante, ou seja, da passagem da "comunidade imaginada" (refere-se a Anderson) para as "pequenas comunidades imaginadas" (p. 47).

${ }^{8}$ É uma preocupação significativa essa pautada na aceitação da relação entre texto e aula, pois, nela, pondera o autor, o texto representaria as expectativas do currículo-base, e a aula, as narrativas de professor e as de alunos.
} 
Podemos sintetizar nosso posicionamento evidenciando nossa apreciação quanto a alguns alcances do PDE, principalmente pelo esforço de aproximar as diferentes esferas do ensino, possibilitando aos professores do ensino básico reavaliarem suas aulas, e contribuírem, na medida do possível, com debates a respeito das implicações epistemológicas. Já no caso dos professores do ensino superior, puderam reaproximar-se do ensino básico e de uma significativa esfera de atuação do historiador. Nos dois alcances, os profissionais podem, enfim, rever seu campo, dialogar com a historiografia e entender o papel do historiador num momento demarcado enquanto momento de "crise da profissão", resultado de anos de enclausuramento de seus profissionais no diálogo limitado aos pares.

Apresentado o potencial do PDE e o significado do recorte regional, a contribuição da produção de um conhecimento dialogal e a valorização da narrativa, cabe, então, destacar aspectos percebidos entre as preocupações epistemológicas de professores orientados e de professores orientadores.

Estamos agora próximos das provocações advindas da análise de Costa (2013), com as quais a autora apresenta o PDE a partir de um dos seus eixos epistemológicos, construído na interpretação das Diretrizes Curriculares Estaduais (DCEs). Ao permitir a análise do Programa mediante aplicação de questionários voltados à trajetória de 42 alunos do programa, distribuídos entre seus anos de formação em História, ou os anos de 1980 ou de 1990, a autora destaca os "[...] usos, significados, dificuldades e negação deste texto curricular oficial"' (p. 53).

Assim como destacou a autora, concordamos com o fato de que as DCEs do Estado acompanham um momento de transformação do campo, recorte este demarcado a partir de 2006, quando tais diretrizes passaram a ser aplicadas no Estado. A própria maneira como a autora aborda as contribuições e a resistência dos alunos diante do estudo desse documento serve aqui de introdução para contextualizarmos a relação epistemológica que se dá entre os professores envolvidos 9 .

Nas conclusões, ao valorizar os saberes mobilizados pelos professores do PDE, a autora aponta ao mesmo tempo para a viabilidade e para a dificuldade da interpretação

9 O documento em questão propõe, para o processo de produção do conhecimento histórico, a aproximação da concepção de consciência histórica de Hüssen, além do debate com as contribuições das correntes históricas, reconhecendo pontos positivos da corrente dos Annales, mas se aproximando da Nova História Cultural e da Nova Esquerda Inglesa. Temos ainda a ênfase no estudo de metodologias, como é o caso das metodologias referentes às fontes orais e imagéticas e a valorização do conhecimento estruturado na "Micro-História" e na construção da "História de Baixo". Todo esse arsenal deveria pautar a formação dos professores da rede nos diferentes cursos de formação, inclusive no curso do PDE. 
do documento e de seus autores - algo também constatado nas oportunidades em estudarmos no programa as DCEs ${ }^{10}$. E podemos avaliar, mais que as contribuições das DCEs, a contribuição de todo o processo formativo e de intervenção, os ganhos de sua análise e as resistências quanto à sua utilização na formação continuada, e assim chegamos à seguinte questão: - Como se dá a apropriação dessa e de outras leituras teóricas no PDE? E, ainda: - Estariam professores orientandos e professores orientadores construindo juntos uma fundamentação suficiente para a sequência das atividades, isso durante a fase de produção de material didático e da sua aplicação nos colégios? Afinal, dominar teorias, por um lado, e conhecer o cotidiano, entenda-se, fontes, por outro, levariam elas por caminhos diferenciados de interpretação da história regional? - Representariam um conhecimento dialogal? - Estariam, professores orientadores e professores orientandos do PDE, num mesmo vértice do triângulo apresentado por Nóvoa? - Com quais ritmos se aproximam do saber pedagógico e do saber do conteúdo?

\section{Proximidades e distanciamentos: conhecer a história e produzir a história}

Tenta-se aqui, assumindo o cuidado com o risco de esquematizações dicotômicas, situar, nos meandros da relação orientando e orientador, os objetivos epistemológicos reconhecidos e experienciados por nós no PDE. E, com isso, transitamos entre a abordagem do reconstrutivismo, a do construtivismo, e a do desconstrutivismo (CARDOSO; VAINFAS, 1997, p. 4). De acordo com os autores estaria o reconstrutivismo atrelado aos esforços da corrente metódica do século XIX, preocupada com a parcialidade da pesquisa, da qual se chegaria à reconstrução, isto a depender das fontes primárias conseguidas e tratadas com o devido rigor metódico, do passado; o desconstrutivismo atrelado às influências da "virada linguística" ocorrida a partir da década de 1970, pautada no estudo das narrativas e nos discursos que a compunham; por sua vez, o construtivismo, a perspectiva adotada pelos autores, preocupado com um posicionamento do qual se atem às fontes e ao devido rigor do

10 Para a autora, essas dificuldades são de ordem geracional quanto ao período de formação dos professores, quanto ao tempo limitado do Programa (dois anos) e quanto às intencionalidades dos profissionais envolvidos quando se voltam ao estudo do campo no decorrer do Programa. 
método, porém, sem que se ignore com isso os discursos e a devida interferência do autor-pesquisador no resultado final de sua pesquisa ${ }^{11}$.

A abordagem ganhou mais contornos após a aplicação de um questionário entre os nossos orientandos ${ }^{12}$. A metodologia utilizada exprime, a partir de 11 questionários respondidos, mais do diálogo com a formação PDE da qual estamos a tratar pelo viés qualitativo.

Quando questionados sobre o papel do PDE diante de seus objetivos profissionais/sociais e do suposto papel do Programa para seus orientadores, as diferenças e os posicionamentos foram evidentes. É o que representa a análise da questão a seguir:

Questão $n^{\circ} 7$ - Enunciado: No seu PDE, a prioridade de seus professores em relação à sua formação, foi a de: a- destacar/ensinar como métodos e teorias são necessárias para produção de pesquisa histórica; b- destacar/ensinar métodos e teorias necessárias para a construção de material didático; c- destacar/ensinar métodos e teorias importantes para seu aprimoramento intelectual e profissional; dcontribuir com o desenvolvimento de uma pesquisa histórica inovadora e significativa para a sua localidade; e- desenvolver uma pesquisa histórica significativa para a produção de aulas de História; fcontribuir com o desenvolvimento de recursos didáticos no intuito de inovar as aulas de História.

Os resultados foram cruzados com as respostas de outra questão:

Questão $\mathrm{n}^{\circ} 8$ - Enunciado: Dentre as abordagens epistemológicas citadas a seguir, destaque as principais contribuições do Programa de para a sua formação: a- reinterpretar a realidade vivida pelos seus alunos; b- desenvolver uma pesquisa histórica significativa para a produção de aulas de história; c- reconstruir, o mais próximo possível, a realidade estudada no tempo e no espaço; d- reconstruir, a partir das fontes selecionadas, o passado estudado; e- contribuir com o desenvolvimento de recursos didáticos no intuito de inovar as aulas de História; f- permitir ao aluno o acesso ao debate em torno do conhecimento histórico no intuito de que ele analise criticamente a sociedade em que vive.

As alternativas foram enumeradas de acordo com a sua ordem de importância.

$\mathrm{Na}$ questão $\mathrm{n}^{\circ}$ 7, a ênfase no papel do professor orientador fora aprestada no

11 A tendência à desvalorização do reconstrutivismo em detrimento do desconstrutivismo passa a ser questionada nos estudos do campo realizado na obra citada, mesmo que eles indiquem uma defesa do construtivismo, acepção a partir da qual também procurarmos construir nossas pesquisas.

${ }^{12}$ A metodologia aplicada não tem alcance quantitativo e isso não implica desrespeito às contribuições do campo da estatística - contribuições infelizmente não tentadas no nosso caso - . Os questionários não se destinaram à produção de estudo pautado nessa metodologia, mesmo que assumida numa perspectiva qualitativa e não quantitativa. A intenção de sua aplicação se deve à tentativa de sistematização e de aproximação do olhar dos orientandos naquilo que escaparia à experiência de orientação. 
apontamento dos objetivos: "destacar/ensinar como métodos e teorias são necessárias para produção de pesquisa histórica" e "destacar/ensinar métodos e teorias necessárias para a construção de material didático". Já quando trataram de seu papel no Programa, na questão $\mathrm{n}^{\circ} 8$, enfatizaram, do contrário, “desenvolver uma pesquisa histórica significativa para a produção de aulas de história" e "contribuir com o desenvolvimento de recursos didáticos no intuito de inovar as aulas de História”. Numa síntese do cruzamento das respostas, ressalta-se o fato de os professores orientandos se colocarem em lugares diferentes dos lugares dos professores orientadores.

Tal discrepância entre as respostas indica para o fato de que, ao falarem de si, partem da preocupação com a qual delimitamos a problemática que inicia o artigo, qual seja, voltada à possibilidade da investigação de um passado próximo que se conhece (relativo à história dos alunos e/ou do município), isto feito sem um aval advindo de um "domínio" do debate conceitual (teórico), mas, sim, pela autoridade do conhecer, do ser morador, ou ainda da própria facilidade de acesso às fontes - leia- se: do domínio dos fatos e eventos ocorridos no município e/ou na região a serem analisados. Algo pautado na autoridade que resulta da experiência em sala de alua. Essa conjunção de fatores indica maneiras de lidar com metodologias. É a capacidade de os professores e alunos dos colégios se dizerem sabedores da história local. Esse domínio difere então da missão do orientador, que seria, por sua vez, a de repassar o arsenal teórico e metodológico que dominam. Poderíamos complementar, afinal, que eles desconheceriam, nessa analogia, na maioria dos casos, as situações históricas investigadas. Ou seja, dominariam a teoria, mas não dominariam as fontes.

Podemos, então, voltar ao exemplo da entrevista que abriu o artigo com o exmorador de uma das ilhas de Porto Camargo e avaliar a situação da professora e a nossa própria diante daquela pesquisa. Para o professor PDE, ao lidar com a produção do conhecimento histórico diante da sua suposta limitação e das cobranças das leituras teóricas trazidas pelos orientadores, ele teria aí um trunfo - um trunfo vivido sutilmente diante dos orientadores, estes, em muitas das vezes, desconhecedores das narrativas recolhidas, como, por exemplo, desta que abre nossa escrita. Talvez isso implique uma revalorização do reconstrutivismo por parte dos orientandos, pois eles, sim, ao terem acesso a diferentes fontes poderiam se colocar no lugar dos moradores estudados. Ou, ainda, talvez indique uma intensificação na possibilidade de interpretar fenômenos pela vivência e assim "reconstruí-los", e cabe destacar, como o fazem Cardoso; Vainfas (1997, p. 12), que a revalorização das pesquisas acadêmicas - das quais o PDE se 
aproxima - representa certa resistência à desconstrução do objeto pela teoria-método (e, nesse caso, para os autores, apesar da contribuição à construção do campo histórico, não tivemos, nas quatro últimas décadas, um paradigma de pesquisa reconstrutivista), ou seja, resistência ao desconstrutivismo e aproximação ao reconstrutivismo, leitura esta percebida também no PDE.

\section{Entre o desafio historiográfico e as exigências da pesquisa: um exemplo de caso}

Assumimos a contribuição e alcances do PDE, entretanto suas contribuições nos chamam a refletir exatamente a relação entre ensino superior e professores da rede básica, agora mais próximos da exemplificação dos desafios surgidos no processo de orientação e das aulas. As respostas do questionário, no qual situaram orientadores de um lado, preocupados supostamente com a teoria, e orientandos de outro, supostamente preocupados com o acesso e tratamento metódico de suas fontes, indicam menos para a afirmação de tal dicotomia e mais para as aproximações destas categorias na e pela pesquisa e produção do material didático. Mais que extremos do desconstrutivismo e do reconstrutivismo chegamos sim ao apontamento de uma produção dialogal.

Selecionamos para o momento a linha de pesquisa "História Ambiental", com o trabalho apresentado no início do texto sob o título de "Memórias dos Ilhéus do Porto Camargo, Rio Paraná (1984-2013): cotidiano, trabalho e sala de aula" - trabalho a ser publicado pela Secretaria de Educação do Paraná (SEED/PR), no Portal "Dia a Dia Educação", no campo referente às publicações de artigos produzidos no PDE.

A aproximação com a História Ambiental possibilitou a construção de uma pesquisa com memórias no cotejamento delas entre si e com outras fontes. Problematizando o estado da transformação ambiental, lidou-se tanto com o discurso do progresso quanto com o discurso ecológico, movimento buscado nas ressignificações feitas pelos alunos a respeito das práticas dos familiares e de outros moradores do munícipio e região, a depender da pessoa indicada ${ }^{13}$.

${ }^{13}$ Das três orientações desenvolvidas ligadas a essa linha, uma aqui destacada é referente à análise da recente história do distrito de Porto Camargo, no Paraná. Em linhas gerais, cabe destacar inicialmente o fato de que muitos dos alunos, entre 13 e 15 anos de idade na maioria, desconheciam detalhes cotidianos e políticos do passado recente da localidade, mas anterior à criação do Parque Nacional de Ilha Grande (PNIG) em meados dos anos 1980. E acreditamos que isto por si justificaria o desenvolvimento do projeto. 
No desenvolvimento da atividade, a professora procurou historiar um recorte local, o Porto Camargo nas últimas quatro décadas, e destacar o período no qual ilhéus vivenciaram a transformação do lugar em Parque Nacional de Ilha Grande. No diálogo com moradores e familiares dos alunos foram sendo percebidas as resistências históricas de um passado recente em se aderir ao controle do extrativismo e da pecuária e a respectiva aproximação com o turismo. Ali, foi um desafio lidar com o discurso ecológico diante das cobranças legais, cobranças essas que implicaram, e ainda implicam, diretamente, confrontos com a prática cotidiana dos moradores ${ }^{14}$. Fazer entrevistas foi uma das atividades constantes da metodologia empregada no projeto para buscar o significado das transformações da infraestrutura, algo representado, no início do capítulo, pelo aparente paradoxo do entrevistado, situado entre "viver melhor o hoje" em contraponto com "a felicidade do ontem" (antes da criação do parque).

Nas suas particularidades de pesquisa, a professora cobrou dos alunos que lidassem com a relação entre História e memórias, e foi justamente diante desse olhar que foram problematizadas as "dificuldades", no diálogo pautado num contraponto entre "a vida de antes do Parque" e "a vida após a construção do Parque".

Aqui nos interessam, porém, as "dificuldades" apresentadas no decorrer das orientações no tocante às resistências de leituras teóricas e metodológicas e ao apego às fontes locais conseguidas, fatores que ditaram o posicionamento da professora em sua busca, a priori, de (re)construção de parte da história daquela localidade, isto sem deixar de destacar nossos esforços para que fosse realizada a produção de um material didático correspondente e a respectiva intervenção em sala de aula. Todos esses desafios foram positivos. E uma vez já problematizada tal resistência, passemos, em forma de conclusão, a alguns resultados do projeto.

No projeto buscou-se uma aproximação com o real, e este posicionamento estruturou a busca da professora moradora da localidade pelo contato com fontes e com documentos, fotografias e entrevistas produzidas - numa atitude de orientação valorizada, vale insistir, pelo fato de essa professora se dizer uma "conhecedora" da realidade local-regional. Quanto aos alcances da orientação - reconhecendo aqui a limitação advinda da falta de contato direto do orientador com as os sujeitos estudados , cobrou-se, por um lado, a ênfase nos métodos da pesquisa com o direcionamento de

${ }^{14}$ Esses discursos ecológicos trouxeram aos moradores um novo comportamento frente à natureza e ao território e foram avaliados diante de diferentes formas de resistências dos moradores tradicionais; isso foi o que direcionou a maioria das entrevistas realizadas pelos alunos. 
leituras sobre análises imagéticas e transcrição de narrativas orais, e por outro, análises teórico-epistemológicas que compõem a atividade, neste caso com a ênfase no estudo da relação entre História e Memória e da revisão do campo da História Ambiental.

Percebemos novas posturas diante da natureza. Dentre os resultados das atividades, a abordagem reflexiva esteve imbuída de uma crítica às leituras binárias e que viessem a resumir a migração das ilhas para o centro político do distrito de Porto Camargo meramente pelos ganhos materiais de hoje. Dada essa reflexão crítica, foi possível indicar a complexidade dessa migração, de como os moradores locais familiares dos alunos na maioria dos casos - indicaram perdas na saída das ilhas, na regulamentação da atividade de pesca e no fim da pecuária após as cobranças ambientais do Parque; todavia, também enfatizaram a melhoria nas condições materiais e, na maioria dos casos, certo orgulho pela nova postura ecológica assumida na localidade.

Ao lidarmos com memórias, logo surgiu a preocupação do significado do próprio uso dessas memórias. As apresentações do que seriam aquelas pesquisas e as autorizações para gravar, a transcrição e a autorização final nos dão conta da avaliação do significado e da expectativa do entrevistado com o produto final. Isso nos direcionou a aplicar as entrevistas numa esfera dialogal, de maneira a considerar, sobretudo, o comportamento ético do processo de produção da entrevista, e lidar com as expectativas dos entrevistados, com a nossa e ainda com as do futuro leitor (PORTELLI, 1998), uma abordagem melhor exemplificada a partir do conceito de "memórias divididas" $(\text { Idem })^{15}$.

A análise e a reflexão dessas leituras citadas estruturaram o envolvimento de todos no projeto; e, evidentemente, contaram com o conhecimento dos moradores professora, e alunos inclusive, e cada um faz a devida ressignificação do debate. Aqui está nossa apresentação da postura epistemológica, postura que norteou a relação entre professores orientandos e professores orientadores diante da pesquisa e ensino de História. Trata-se de algo que diz respeito aos ritmos da apropriação e à ressignificação de tais leituras.

${ }^{15} \mathrm{O}$ debate também enveredou pela relação entre Memória e Identidade. Assim, com base nas lições de Candau (2011), construiu-se uma relação de análise dialogal entre memórias fortes - do ritmo de vida em busca do progresso da pecuária e das formas de antes de se pescar -, com memórias fracas - como as que se relacionam com as demandas do turismo e adaptação das formas de pesca. 


\section{Considerações finais}

O alcance do projeto apresentado nos serve de considerações finais. Todos os envolvidos se colocaram, cada um segundo seu ritmo, a interpretar a fala do morador entrevistado. Nesse processo destaca-se a produção do conhecimento histórico, tendo, por um lado, uma ênfase atribuída à preocupação com as fontes - numa alusão ao potencial reconstrutivista da pesquisa de campo da professora, e, por outro lado, uma possível aproximação da tentativa de desconstrução de discursos, como o do progresso, por exemplo, a partir da leitura de métodos e de teorias.

Aqui cabe uma ressalva. Não podemos defender um hiato entre professores orientadores e professores orientandos no PDE. Isso perigosamente reafirmaria que uns, os primeiros, focados num desconstrutivismo teórico e historiográfico, estariam cegos às transformações e às permanências de nível local que eles próprios investigam, e que outros, os professores-alunos, focados na sua capacidade empática de se colocarem no lugar da população local/regional - que bem conhecem devido ao fato de lidarem com as fontes referentes aos acontecimentos locais/regionais, cairiam numa ilusão metódica que tomaria forma no reconstrutivismo. Somente com esta negativa pudemos questionar a aparente dicotomia entre os questionários analisados e a nossa prática de orientação.

Assim avaliamos o que significou ouvir pescadores que hoje se relacionam com o turismo e assumem novas identidades ao se apropriarem e produzirem memórias de suas histórias, na Ilha e no Porto Camargo. A dialogicidade das relações entre a professora orientanda, a(s) sua(s) turma(s), e o professor orientador direcionaram o entendimento dos processos formativos e os contornos que o projeto ganhou diante das camadas institucionais e entre elas - neste caso contribui com a produção do conhecimento histórico regional no ensino e na pesquisa.

Tal análise, tomada aqui pelas problemáticas e pelos distanciamentos epistemológicos, não impede de, enfim, situarmos professores orientadores e professores orientandos no mesmo vértice do sistema educacional moderno, preocupados da mesma forma com saberes dos conteúdos advindos da pesquisa histórica e com as práticas de orientação dialogal.

\section{Referências}


CERRI, Luis Fernando. Ensino de História e concepções historiográficas. In: Espaço Plural. V. 10, n. 20, p. 149-154, 2009.

CANDAU, Joël. Memória e identidade. São Paulo: Contexto, 2011.

CARDOSO, C.; VAINFAS, R. Domínios da história: ensaios de metodologia. Rio de Janeiro, Campus, 1997.

COSTA, Maria de Paula. O ensino de história no século XXI: a perspectiva dos professores participantes do Programa de Desenvolvimento Educacional do Paraná (PDE) em relação às Diretrizes Curriculares da Educação Básica de História (DCEs). In: Antítese, v. 6, n. 12, p. 53-75, 2013.

ESCORSI, Valerio Mairon. Para que serve a história ensinada? A guerra de narrativas, a celebração das identidades e a morte da política. Revista Territórios \& Fronteiras, Cuiabá, v. 6, n. 3, p. 39-52, dez. 2013.

JENKINS, Keith. A história repensada. São Paulo: Contexto, 2001.

HALL, Stuart. Identidade cultural na pós-modernidade. 7. ed. Rio de Janeiro: DP \& A, 2002.

MATTOS, Ilmar Rohloff de. "Mas não somente assim! Leitores, autores, aulas como texto e o ensino-aprendizagem de História". In: Tempo, v.11, n. 21, p. 5-16, 2007.

NÓVOA, A. (org.) Profissão professor. 2 ed. Porto: Porto Editora, 1999.

PARANÁ. Dia a Dia Educação: Portal Educacional do Estado do Paraná. Disponível em: <http://www.diaadia.pr.gov.br/>. Acesso>. Acesso em: 15 fev. 2015.

PORTELLI, Alessandro. O massacre de Civitella Val di Chiana (Toscana: 29 de junho de 1944): mito, política, luto e senso comum. In: AMADO E FERREIRA. Usos e abusos da história oral. Rio de Janeiro: FGV, 1998.

RICOUER, Paul. A memória, a história, o esquecimento. Campinas, SP: Edunicamp, 2007.

\section{Como referenciar este artigo}

PAGLIARINI JUNIOR, Jorge. A história na e pela sala de aula: a relação entre professores do 'ensino básico' e do 'ensino superior' a partir do PDE-PR. Revista Ibero-Americana de Estudos em Educação, Araraquara, v. 12, n. 2, p. 884-899, 2017. Disponível em: <http://dx.doi.org/10.21723/riaee.v12.n2.8461>. E-ISSN: 1982-5587.

Recebido em: 12/03/2016

Aprovação final em: 27/03/2017 